\title{
Study of the biorreduction of halogenated enones by supported microorganisms
}

Paulo J. S. Moran (PQ), Bruno R. S. de Paula (PG), Fernanda S. Povreslo (IC).

\begin{abstract}
The catalytic efficiency of enzymes from Saccharomyces cerevisiae can be applied to biocatalysis ${ }^{1}$. The main enzymes found in S.cerevisiae are Alcohol Dehydrogenases (ADH) and Old Yellow Enzymes (OYE). ADH and OYE rapidly reduce compounds such as 3-bromo-4-phenyl-3-buthen-2-one thus complicating the acquisition of their reaction intermediates, such as $\alpha$-bromoketone. Through the use of biphasic systems and immobilisation techniques it is possible to increase the chemoselectivity of these reactions in order to obtain $\alpha$-bromoketone by preferential olefin reduction by OYE.
\end{abstract}

Key words: Immobilisation, Saccharomyces cerevisiae, 3-bromo-4-phenyl-3-buthen-2-one.

\section{Introduction}

Biocatalysis involving S.cerevisiae is largely employed in organic synthesis due to the efficiency of the enzymes ${ }^{2} \mathrm{ADH}$ and OYE. Carbonyl compounds with an electronwithdrawing group, e.g. 3-bromo-4-phenyl-3buthen-2-one (1), are rapidly reduced by the actions of $A D H$ and OYE, which complicates the process of obtaining the $\alpha$-bromoketone intermediate (2). Immobilisation of the S.cerevisiae in a calcium alginate gel allows for the confinement of the cells inside a physical structure which not only decreases the amount of available 3-bromo-4-phenyl-3-buthen-2-one, but also isolates the reduction pathway and the number of purification steps of the product.

\section{Results and Discussion}

Biphasic systems of water-solvent resulted in the best rates of olefin reduction and decreased the reaction velocity of ketone reduction (Fig. 1). In order to optimise the production of $\alpha$-bromoketone, the following conditions were optimised: mass of cells, proportion water-solvent and volume of solvent.

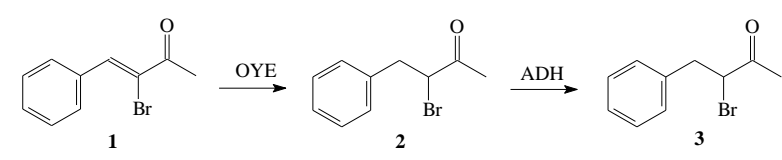

Figure 1. Reduction of 3-bromo-4-phenyl-3buthen-2-one by Saccharomyces cerevisiae

The optimum condition was that of a biphasic system of water-ionic liquid [bmim $\left(\mathrm{PF}_{6}\right)$ ] at a ratio of $5: 1$ with $5 \mathrm{~g}$ of cells. This resulted in an increase of $\alpha$-bromoketone and near total consumption of 3-bromo-4-phenyl-3-buthen-2-one in 24 hours (Fig. 2). These data were tested by scaling up the reaction $(5 x)$ to assess its reproducibility. The substrate and products were analysed by gas chromatography-mass spectrometry.

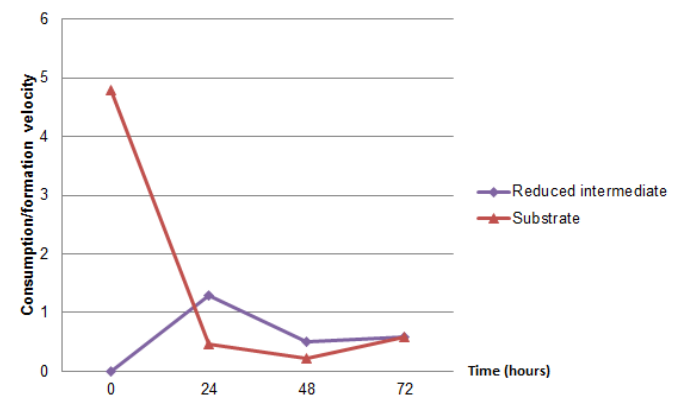

Figure 2. Profile of 3-bromo-4-phenyl-3-buthen-2one reduction by $S$.cerevisiae immobilized in calcium alginate gel using water-[bmim $\left.\left(\mathrm{PF}_{6}\right)\right](5: 1)$ as solvent

\section{Conclusions}

The desired $\alpha$-bromoketone was obtained through immobilisation of the yeast in calcium alginate gel using water-[bmim $\left.\left(\mathrm{PF}_{6}\right)\right]$ (5:1) as solvent, allowing the isolation of $\alpha$-bromoketone in appropriate quantity for analyses.

\section{Acknowledgement}

The authors thank CNPq and FAPESP.

\footnotetext{
${ }^{1}$ Nelson, D. L.; Cox, M. M.; Lehninger: Principles of biochemistry, $3^{\text {rd }}$ Ed., 2002, 189.

${ }^{2}$ Zampieri, D.S.; de Paula, B.R.S.; Zampieri L.A.; Vale, J.A.; Rodrigues, J.A.R.; Moran, P.J.S. J. Mol. Catal. B Enzym. 2013, 85, 61.
} 